\title{
Large-scale genetic patchiness among NE Atlantic populations of the brittle star Ophiothrix fragilis
}

\author{
D. Muths ${ }^{1,2, *}$, D. Jollivet ${ }^{1,2}$, F. Gentil ${ }^{1,2}$, D. Davoult ${ }^{1,2}$ \\ ${ }^{1}$ Université Pierre et Marie Curie-Paris VI, Laboratoire 'Adaptation \& Diversité en Milieu Marin', 29682 \\ Roscoff Cedex, France \\ ${ }^{2}$ CNRS UMR 7144, Station Biologique de Roscoff, BP 74, Place Georges Teissier, 29682 Roscoff Cedex, France
}

\begin{abstract}
The brittle star Ophiothrix fragilis (Abilgaard, 1789) constitutes a heterogeneous morphological group that can be subdivided into 4 varieties. The species is also characterized by high demographic variability. The present study explores the possibility of genetic patchiness arising due to admixture of varieties or recruitment heterogeneity. We sequenced a portion of the mitochondrial cytochrome oxidase subunit I (mtCOI) gene and genotyped 7 allozymes from 21 populations of the 2 most common varieties. While mtCOI analyses showed that all the varieties grouped together with virtually no divergence among them $(<1 \%)$, a clear divergence $(18.6 \%)$ was evident between the northern Atlantic populations and individuals collected in the Mediterranean and along the Galician coast. Conversely, canonical analysis indicated that classification by variety explained a substantial part of the allozyme variance. Within O.f. pentaphyllum, no clear pattern of geographic structure was observed around the British Isles, with neighbouring populations often showing more genetic differentiation with one another than with distant populations. This either reflects admixture of cryptic lineages/species, diversifying selection due to contrasting habitats, or spatial and/or temporal admixture of genetically differentiated cohorts produced from isolated populations. The latter hypothesis is reinforced by the fact that significant haplotype frequency differences were recorded between larvae, juveniles and adults within the same locality. Providing that time-isolated clades co-occur within populations, the variation in the number and intensity of recruitment events must impact local genetic structure extensively and induce chaotic genetic patchiness at a large spatial scale.
\end{abstract}

KEY WORDS: Echinoderm · Allozyme - MtCOI - Population dynamics · Ecotypes · Dispersal · Recruitment Resale or republication not permitted without written consent of the publisher

\section{INTRODUCTION}

Connectivity between local populations of benthopelagic species is primarily ensured by the larval stage. Considering dispersal, 2 notions are frequently confounded (Kinlan et al. 2005): the maximal dispersal a larva can achieve (rare events but with a consequent impact on range expansion and the colonisation of new areas) is often confused with the effective larval dispersal (frequent events that play a crucial role in population demography). Comparative studies of closely related species with contrasting larval lifespans show that the genetic structure of a given species is not nec- essarily correlated to its dispersal ability. While population connectivity often conforms to what can be expected based on larval lifespan (McMillan et al. 1992, Arndt \& Smith 1998, Kyle \& Boulding 2000), the opposite situation is also encountered. Certain species with a long planktonic phase have a more pronounced genetic structure than species with direct development (Todd et al. 1998, Marko 2004, Bowen et al. 2006). Effective dispersal ability is affected by external factors such as habitat fragmentation (Gaines \& Bertness 1992), larval mortality (Rumrill 1990), and/or local marine currents (Cowen et al. 2000, Ellien et al. 2000, Sponaugle et al. 2002). 
When dispersal is limited, self-recruitment plays a major role in population replenishment; in this case, genetic differentiation is primarily associated with genetic drift and depends on the effective size of each local population. The expected isolation-by-distance pattern can be masked either by large variations in population size or by chaotic arrivals of larval pools from different origins (if settlers do not crossbreed among cohorts). Alternation of self- and allo-recruitment phases has therefore been proposed to explain microgeographical genetic heterogeneities in large 'panmictic' populations (Johnson \& Black 1982). This pattern, called 'chaotic genetic patchiness' (Johnson \& Black 1982), has often been viewed as the result of slightly differentiated settler cohorts entering the population (Hedgecock 1994, Moberg \& Burton 2000, Hellberg et al. 2002). Alternative explanations to 'chaotic' genetic patchiness include diversifying selection arising from microhabitat heterogeneity (Chevillon et al. 1998, Eckert 2007) or cryptic species admixture (Knowlton 1993).

The gregarious brittle star Ophiothrix fragilis (Abilgaard, 1789) is widely distributed in the NE Atlantic Ocean and Mediterranean Sea (Koehler 1921). The genus Ophiothrix, however, shows a very high level of inter- and intraspecific variation in morphology (Koehler 1921), which has led to many taxonomic debates over the last century (Koehler 1921, Guille 1964). More recently, on the basis of $16 \mathrm{~S}$ rDNA sequences, Baric \& Sturmbauer (1999) identified 2 distinct mitochondrial lineages within each of the 2 welldiagnosed species $O$. fragilis and $O$. quinquemaculata, but virtually no genetic differences between the 2 species within either the Mediterranean or the Atlantic. They suggested that each lineage represents a true biological species, both of which consist of 2 morpho/ ecotypes. Morphological differences could be indeed explained by phenotypic plasticity associated with the strength of marine currents rather than with diagnostic genetic characters: O. fragilis prefers hard substrates and strong current exposure whereas O. quinquemaculata is mainly found on soft substrates with moderate current exposure (Baric \& Sturmbauer 1999). Although $O$. fragilis individuals from the NE Atlantic belong to the same species, they do not constitute a homogeneous morphological group. Instead, they are subdivided into 4 morphological varieties described by Koehler (1921) according to their colouration and the length of their arms, both characteristics allegedly linked to ecological factors (Allain 1974).

The species has a high fecundity (Lefebvre 1999), and larval lifespan is estimated to be between 21 (Morgan \& Jangoux 2002) and 26 d (McBride 1907). This moderately long larval stage, coupled with the strong easterly residual currents in the English Channel
(Salomon 1990), may ensure connectivity between distant populations in this area. However, dispersal models suggest that a non-negligible amount of larval retention occurs at some locations in the English Channel, thereby favouring self-recruitment (Lefebvre et al. 2003). Conversely, previous demographic surveys conducted in Dover Strait (Davoult et al. 1990) demonstrated the occurrence of distinct recruitment events. Recruitment heterogeneity raises an intriguing question on the origin of the settlers, especially since the English Channel represents a well-documented biogeographic transition zone between the Boreal and Lusitanian provinces (Cabioch 1968, Briggs 1995). Successive recruitment events during the year may either be the consequence of reproductive asynchrony (individuals are not mature at the same time) or the result of the arrival of settlers from allochthonous origins, which may lead to a possible Wahlund effect if they are reproductively isolated.

First, the taxonomic status of Ophiothrix fragilis varieties needs to be assessed. Most populations are monotypic, and varieties are rarely found in sympatry (Allain 1974). If varieties represent separate taxonomic units, hybridizing taxa or locally adapted populations, the distribution of varieties would lead to genetic patchiness, possible linkage disequilibria and heterozygote deficiencies. The present study explores the genetic differences among varieties, and whether distinct mitochondrial lineages can be found within the southern and northern Atlantic populations. We then evaluate the effective level of genetic connectivity between populations in the NE Atlantic to address the following questions: Does the genetic structure conform to expectations based on larval lifespan, hydrodynamic modelling, and/or population dynamics? Is the genetic structure locally affected by recruitment heterogeneity? For these purposes, we sequenced a $542 \mathrm{bp}$ fragment of the mitochondrial cytochrome oxidase I (mtCOI) gene and genotyped a total of 868 individuals at 7 polymorphic allozyme loci over the whole geographic range of the 2 most common varieties of $O$. fragilis (21 sites located at various depths from the south of Brittany to the North Sea). In addition, the population dynamics of 1 of these varieties was surveyed in parallel at 3 distinct well-known localities in the English Channel.

\section{MATERIALS AND METHODS}

Identifying varieties according to Koehler (1921) and Allain (1974). Four varieties have been initially described: Ophiothrix fragilis abildgaardi, O. f. echinata, O. f. lusitanica and O. f. pentaphyllum. Of these, $O$. fragilis pentaphyllum is the most commonly ob- 
served, particularly because it constitutes nearly all dense subtidal beds of brittle stars (i.e. $>1000$ ind. $\mathrm{m}^{-2}$ ) in the NE Atlantic, which are stable both in time and space (Brun 1969, Broom 1975, Davoult \& Gounin 1995, Ellis \& Rogers 2000). Consequently, O. f. pentaphyllum is the most studied variety of $O$. fragilis, in terms of its population dynamics (Davoult et al. 1990), larval development and dispersal (Lefebvre \& Davoult 2000, Lefebvre et al. 2003) and reproduction (Morgan \& Jangoux 2002, 2005). O. f. pentaphyllum is also the most easily distinguishable variety by the length of its arms (i.e. for a given disc size, arms are twice as long as those of other varieties) and by its bright, warm coloration (mainly yellow and pink, with red rings). Moreover, this variety has never been reported in the intertidal zone, while the 3 other varieties are encountered mainly in the intertidal zone and also in deeper waters, but always at a very low density $\left(<10\right.$ ind. $\mathrm{m}^{-2}$; Nataf 1954). These 3 varieties are all morphologically similar, with short arms and dark, cold colours (mainly brownish and greenish). Of these 3 varieties, the most common one is O.f. echinata, typically present in the intertidal. The morphological and ecological characteristics of O. f. lusitanica and O. f. echinata are the same, except that the former has a pentagon-shaped disc and the latter has a round disc. Disc shape, however, is seemingly largely influenced by gonad development (authors' pers. obs.), and therefore cannot be used as a criterion for differentiating these 2 varieties. Nevertheless, since individuals with pentagonal discs were never observed in our samples, all individuals sampled in the intertidal zone were considered to be O. f. echinata. It is worth noting that the variety O. f. lusitanica is very rare (Allain 1974). The last variety, O. $f$. abildgaardi, represents a geographic form restricted to the North Sea and Norwegian coasts.

Population sampling. Sampling was done throughout the Atlantic range of the species from the intertidal down to the deep subtidal $(100 \mathrm{~m})$. However, Ophiothrix fragilis samples were mostly collected from subtidal brittle star beds. The remaining subtidal samples were comprised of scattered individuals living in maerl beds or on pebble substrata. Subtidal samples were obtained by dredging the hard sediment with a 'Rallier-du-Baty' dredge (Cabioch 1968) over 25 to $100 \mathrm{~m}$ transects. Populations from the Irish Sea were sampled in April/May 2004, those from southern Brittany in March, June and September 2005, and populations from the English Channel were sampled in 2004. Intertidal populations were sampled by collecting scattered individuals on the rocky shore at low tide in 2005. In addition to the 21 main populations, individuals from the western and eastern coasts of Spain, and from Norway and Sweden were kindly provided by marine laboratories at our request, and constituted 4 reference groups. The sampling locations are shown in Fig. 1, and geographical coordinates of all samples are given in Table 1. Population descriptors such as variety, bottom type and depth, as well as locality, are also given in Table 1. After sampling, individuals were directly frozen in liquid nitrogen for later use in molecular analyses. Each individual was thereafter separated into 2 parts: the arms were kept for mitochondrial analyses, while the disc was used for allozyme starch-gel electrophoresis.

Another sampling scheme involved the collection of larvae at Roscoff (France) by trawling over the whole $67 \mathrm{~m}$ water column using a $200 \mu \mathrm{m}$ dip net covering a surface of $1 \mathrm{~m}^{2}$, in August 2005 (the only date at which larvae were identified during a survey carried out between May and October 2005). The larval samples were composed of 2 to 8 arm pluteus larvae, meaning that all larvae collected were $<10$ d old (Morgan \& Jangoux, 2005). Since settlement occurs at about $3 \mathrm{wk}$ of larval life, these larvae were not ready to settle just after the sampling date. But marine currents in this area favour retention of larvae (Lefebvre et al. 2003). It

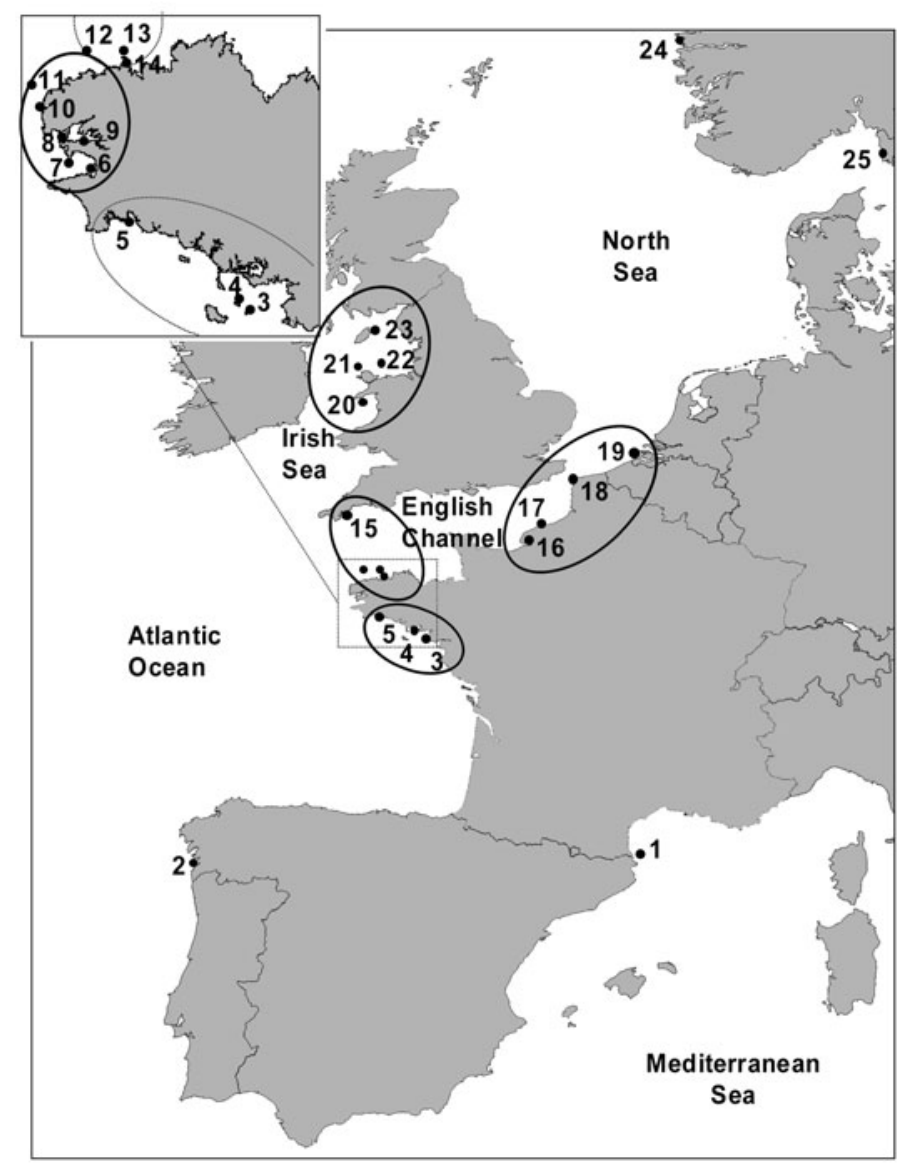

Fig. 1. Geographic locations of 25 Ophiothrix fragilis populations used in the study. Population descriptors in Table 1 
Table 1. Ophiothrix fragilis. Population names, labels, geographic locations, variety composition, habitat type and depth. P, E and A: pentaphyllum, echinata and abildgaardi varieties, respectively; DBO: dense bed on pebbles; MBO: maerl bed with scattered individuals; ROC: rocky shore (intertidal and subtidal zones)

\begin{tabular}{|c|c|c|c|c|c|c|c|c|}
\hline & No. & Label & Population & Latitude & Longitude & Variety & Habitat & Depth (m) \\
\hline \multirow[t]{2}{*}{ Southern Europe } & 1 & Med & Mediterranean & $42^{\circ} 29.23^{\prime} \mathrm{N}$ & $3^{\circ} 09.15^{\prime} \mathrm{E}$ & $\mathrm{E}$ & ROC & 20 \\
\hline & 2 & Gal & Galicia & $42^{\circ} 46.20^{\prime} \mathrm{N}$ & $8^{\circ} 59.57^{\prime} \mathrm{W}$ & $\mathrm{E}$ & ROC & 0 \\
\hline \multirow[t]{3}{*}{ South Brittany } & 3 & Dig & Hoedig & $47^{\circ} 21.75^{\prime} \mathrm{N}$ & $2^{\circ} 49.35^{\prime} \mathrm{W}$ & $\mathrm{P}$ & $\mathrm{DBO}$ & 11 \\
\hline & 4 & Ho & Houat & $47^{\circ} 24.54^{\prime} \mathrm{N}$ & $2^{\circ} 58.31^{\prime} \mathrm{W}$ & $\mathrm{P}$ & $\mathrm{DBO}$ & 13 \\
\hline & 5 & Tre & Trevignon & $47^{\circ} 52.15^{\prime} \mathrm{N}$ & $3^{\circ} 58.05^{\prime} \mathrm{W}$ & $\mathrm{E}$ & $\mathrm{MBO}$ & 15 \\
\hline \multirow[t]{6}{*}{ Iroise Sea } & 6 & Pen & Pentrez & $48^{\circ} 10.32^{\prime} \mathrm{N}$ & $4^{\circ} 19.55^{\prime} \mathrm{W}$ & $\mathrm{E}$ & $\mathrm{MBO}$ & 15 \\
\hline & 7 & $\mathrm{CCh}$ & Cap de la Chevre & $48^{\circ} 09.02^{\prime} \mathrm{N}$ & $4^{\circ} 29.02^{\prime} \mathrm{W}$ & $\mathrm{P}$ & DBO & 27 \\
\hline & 8 & Cam & Camaret & $48^{\circ} 18.04^{\prime} \mathrm{N}$ & $4^{\circ} 37.02^{\prime} \mathrm{W}$ & $\mathrm{P}$ & $\mathrm{DBO}$ & 22 \\
\hline & 9 & $\mathrm{RB}$ & Rade de Brest & $48^{\circ} 19.22^{\prime} \mathrm{N}$ & $4^{\circ} 23.26^{\prime} \mathrm{W}$ & $\mathrm{P}$ & $\mathrm{MBO}$ & 10 \\
\hline & 10 & IS & Ile Segal & $48^{\circ} 26.29^{\prime} \mathrm{N}$ & $4^{\circ} 46.94^{\prime} \mathrm{W}$ & $\mathrm{E}$ & ROC & 0 \\
\hline & 11 & Por & Portsall & $48^{\circ} 36.20^{\prime} \mathrm{N}$ & $4^{\circ} 49.40^{\prime} \mathrm{W}$ & $\mathrm{E}$ & $\mathrm{ROC}$ & 94 \\
\hline \multirow[t]{4}{*}{ Western English Channel (WEC) } & 12 & Ker & Keremma & $48^{\circ} 46.50^{\prime} \mathrm{N}$ & $4^{\circ} 10.00^{\prime} \mathrm{W}$ & $\mathrm{E}$ & $\mathrm{ROC}$ & 80 \\
\hline & 13 & Ro & Roscoff & $48^{\circ} 47.42^{\prime} \mathrm{N}$ & $3^{\circ} 58.79^{\prime} \mathrm{W}$ & $\mathrm{P}$ & $\mathrm{DBO}$ & 71 \\
\hline & 14 & Rest & Restran & $48^{\circ} 43.70^{\prime} \mathrm{N}$ & $3^{\circ} 58.02^{\prime} \mathrm{W}$ & $\mathrm{E}$ & ROC & 0 \\
\hline & 15 & Ply & Plymouth & $50^{\circ} 21.16^{\prime} \mathrm{N}$ & $4^{\circ} 07.52^{\prime} \mathrm{W}$ & $\mathrm{E}$ & ROC & 2 \\
\hline \multirow[t]{4}{*}{ Eastern English Channel (EEC) } & 16 & Ant & Antifer & $49^{\circ} 58.24^{\prime} \mathrm{N}$ & $0^{\circ} 14.41^{\prime} \mathrm{E}$ & $\mathrm{P}$ & $\mathrm{DBO}$ & 30 \\
\hline & 17 & Pal & Paluel & $49^{\circ} 53.10^{\prime} \mathrm{N}$ & $0^{\circ} 35.10^{\prime} \mathrm{E}$ & $\mathrm{P}$ & $\mathrm{DBO}$ & 30 \\
\hline & 18 & Wx & Wimereux & $50^{\circ} 55.00^{\prime} \mathrm{N}$ & $1^{\circ} 35.00^{\prime} \mathrm{E}$ & $\mathrm{P}$ & $\mathrm{DBO}$ & 31 \\
\hline & 19 & $\mathrm{Be}$ & Belgium & $51^{\circ} 31.00^{\prime} \mathrm{N}$ & $4^{\circ} 00.00^{\prime} \mathrm{E}$ & $\mathrm{P}$ & $\mathrm{DBO}$ & 25 \\
\hline \multirow[t]{4}{*}{ Irish Sea } & 20 & $\mathrm{CB}$ & Cardigan Bay & $52^{\circ} 51.08^{\prime} \mathrm{N}$ & $4^{\circ} 47.48^{\prime} \mathrm{W}$ & $\mathrm{P}$ & DBO & 53 \\
\hline & 21 & WA & West Anglesey & $53^{\circ} 22.95^{\prime} \mathrm{N}$ & $4^{\circ} 59.77^{\prime} \mathrm{W}$ & $\mathrm{P}$ & $\mathrm{DBO}$ & 54 \\
\hline & 22 & Ly & Lyna's point & $53^{\circ} 25.46^{\prime} \mathrm{N}$ & $4^{\circ} 13.13^{\prime} \mathrm{W}$ & $\mathrm{P}$ & $\mathrm{DBO}$ & 31 \\
\hline & 23 & IE & Isle of Man East & $54^{\circ} 01.23^{\prime} \mathrm{N}$ & $4^{\circ} 17.55^{\prime} \mathrm{W}$ & $\mathrm{P}$ & $\mathrm{DBO}$ & 42 \\
\hline \multirow[t]{2}{*}{ Northern Europe } & 24 & Nor & Norway & $60^{\circ} 20.00^{\prime} \mathrm{N}$ & $5^{\circ} 12.00^{\prime} \mathrm{E}$ & $\mathrm{A}$ & ROC & 0 \\
\hline & 25 & Swed & Sweden & $58^{\circ} 15.00^{\prime} \mathrm{N}$ & $11^{\circ} 24.00^{\prime} \mathrm{E}$ & $\mathrm{A}$ & ROC & 46 \\
\hline
\end{tabular}

is therefore not possible to determine if and how these larvae would integrate the Roscoff adult population.

For demographic analyses, sampling was carried out every 2 mo, and, as far as possible, in 2 consecutive years (from November 2003 to October 2005) at 3 contrasting localities in the English Channel: Roscoff, Paluel and Wimereux (Sites 13, 16 and 18, respectively, in Fig. 1).

MtCOI direct sequencing. Total genomic DNA was extracted according to the CTAB extraction protocol as described by Jolly et al. (2003). Species-specific primers for PCR (OF-COIf: 5'CCCATAATGATAGGAG GATT-3'; OF-COIr: 5'-TTGTASYGGCGGTGAAGW-3') were designed from conserved regions of the whole COI gene identified from 10 specimens of Ophiothrix fragilis using 'universal' primers developed for invertebrates (McMullin et al. 2003). Reactions were performed in $27 \mu$ l containing $1 \times$ PCR buffer (supplied with polymerase enzyme), $2 \mathrm{mM} \mathrm{MgCl} 2,25 \mu \mathrm{M}$ of each dNTP, $0.2 \mu \mathrm{M}$ of each primer, $0.5 \mathrm{U}$ of Thermoprime Plus Taq polymerase (Abgene) and $25 \mathrm{ng}$ CTABextracted genomic DNA. Cycling parameters were $94^{\circ} \mathrm{C}$ for $5 \mathrm{~min}$, followed by 40 cycles of $94^{\circ} \mathrm{C}$ for $45 \mathrm{~s}$, $54^{\circ} \mathrm{C}$ for $60 \mathrm{~s}$ and $72^{\circ} \mathrm{C}$ for $70 \mathrm{~s}$, and a final elongation at $72^{\circ} \mathrm{C}$ for $7 \mathrm{~min}$. PCR products were purified before sequencing using BigDye terminator chemistry (Perkin Elmer) and sequenced on an ABI 3100 sequencer, following the manufacturer's protocol. Sequencing was carried out in both directions. Sequences were then checked and edited using Chromas Version 1.6 (McCarthy 1997) and aligned using ClustalW (Thompson et al. 1994) in the BioEdit Sequence Alignment Editor (Hall 1999). GenBank accession numbers of the COI sequences of $O$. fragilis used in the present study ranged from EU582688 to EU583125.

Allozyme electrophoresis. Electrophoretic procedures were performed according to the methods of Pasteur et al. (1987). The frozen body of each Ophiothrix fragilis was homogenised in $250 \mu$ l of grinding buffer (10 mM Tris- $\mathrm{HCl}, 2$ mM EDTA, $0.05 \% \beta$-mercaptoethanol, 0.1 mM PMSF, $0.25 \mathrm{mM}$ sucrose; $\mathrm{pH}$ 6.8), prior to centrifugation at $15000 \mathrm{rpm}(17000 \times g)$ for $12 \mathrm{~min}$. The supernatant was stored at $-80^{\circ} \mathrm{C}$ until electrophoresis. Horizontal enzyme electrophoresis was conducted on $12 \%$ starch gels for 7 allozyme systems using the following buffers: (1) tris-citrate, $\mathrm{pH} 8$ for phosphoglucoisomerase (PGI, E.C. 5.3.1.9), phosphoglucomutase (PGM, E.C. 5.4.2.2), malate dehydrogenase $(\mathrm{MDH}$, E.C. 1.1.1.37), malic enzyme (ME, E.C. 1.1.1.40) and (2) tris-borate-EDTA, pH 8.5 for pyruvate kinase 
(PK, E.C. 2.7.1.40), hexokinase (HK, E.C. 2.7.1.1) and mannose phosphate isomerase (MPI, E.C. 5.3.1.8). Loci were labelled according to their position from the anodal end of the gel, and the most frequent allele was called '100'. Other alleles were labelled according to their mobility relative to allele 100.

Genetic data analyses. Genetic variation among mitochondrial sequences was estimated as follows: for each population, the haplotype $\left(H_{\mathrm{d}}\right)$ and nucleotide $(\pi)$ diversities were examined using DNAsp 4.0 software (Rozas et al. 2003). A neighbour-joining (NJ) tree of haplotypes, based on Kimura-2 parameter distance (Kimura 1980), was constructed using Mega 2.1 software (Kumar et al. 2001), with 1000 bootstrap replicates and the species Ophiocomina nigra as an outgroup (GenBank No. EU496814). Tajima's (1989) D statistic and Fu's (1997) F-statistics were calculated as an index of departure from population equilibrium using DNAsp 4.0 (Rozas et al. 2003). Successive AMOVAs (analysis of molecular variance; Excoffier et al. 1992) were performed using Arlequin 2.0 (Schneider et al. 2001) to test 5 hypotheses on the various factors that may influence the genetic structure of $O$. fragilis (see Table 1): (1) varieties (2 groups: O.f. pentaphyllum and O. f. echinata); (2) geographical groupings (5 groups: South Brittany, Iroise Sea, western English Channel, eastern English Channel and Irish Sea), (3) habitat (3 groups: dense beds of ophiuroids on pebbles, maerl beds with scattered individuals, rocky shore with scattered individuals), (4) depth (2 groups: $\leq 2 \mathrm{~m}$ for intertidal, $>10 \mathrm{~m}$ for subtidal) and (5) cohorts (4 groups: larvae and 2 or 3 groups of juveniles/adults). Geographic groups were defined according to wellknown historical (Dover Strait) or hydrodynamic (Celtic and Ushant fronts) features that may have influenced the migration routes of NE Atlantic species. Depth groups were defined to separate intertidal populations from subtidal ones. Cohorts were identified on the basis of a time-series analysis of size-frequency histograms, between 2004 and 2006 (see following subsection); identified cohorts were divided into several groups: recruits from July 2004, recruits from June 2005 and adults from July 2004 for both sites, larvae from August 2005 for Roscoff and recruits from March 2006 for Wimereux. Pairwise genetic distances $\left(\phi_{\mathrm{st}}\right)$ between samples were estimated using Arlequin 2.0 (Schneider et al. 2001); critical significance levels for multiple testing were corrected using a procedure by Benjamini \& Hochberg (1995). Isolation-by-distance was tested with a Mantel test using Genepop 3.4 (Raymond \& Rousset 1999), and significance was estimated using 1000 permutations. Geographic distances were estimated by calculating linear distances along the coastline between 2 points using Great Circle Calculator (available at www.gb3pi.org.uk/great.html). Pair- wise $\phi_{\text {st }}$ were also calculated between temporal subsamples, and unrooted NJ trees of haplotypes were constructed using individual pairwise distances obtained from these temporal samples.

A canonical discriminant analysis (CDA) was conducted using the R package Vegan-RDA (Oksanen et al. 2008) to identify significant correlations between explanatory variables (ecological characteristics specific to each population, i.e. varieties, geographic position, depth, habitat) and response variables (i.e. allozyme frequencies in populations). CDA was performed on population-level frequencies rather than individualbased genotypes, since no variety admixture (based on morphology) was found in any of the 21 main samples. Explanatory variables were re-coded as a set of binary variables. The level of significance of explanatory variables in structuring populations was tested using a forward-selection procedure on canonical residuals using Monte Carlo permutation tests (999 random permutations), retaining the variables with $\mathrm{p} \times 0.05$. This was computed from the 'forward.sel' function available in the R 'packfor' library (Dray 2004) developed for Canoco (Ter Braak \& Smilauer 2002). Vectors from nonsignificant explanatory variables were excluded from the 2 factorial-axes bi-plot graph.

Allele frequencies, genetic diversity per population and genetic differentiation between populations were estimated from allozymes following classic population estimators implemented in the Genepop 3.4 software (Raymond \& Rousset 1999), such as observed $\left(H_{0}\right)$ and expected $\left(H_{\mathrm{e}}\right)$ heterozygosities (Nei 1987). In addition, allelic richness $\left(R_{\mathrm{s}}\right.$ an estimation of the number of alleles independent of sample size, making it possible to compare samples with different numbers of individuals; in the present case, the shared minimal sample size was 16 individuals) was estimated with Fstat 2.9.3.2 (Goudet 1995). The null hypothesis of independence between loci was tested from statistical genotypic disequilibrium analyses using Genepop 3.4. Deviations from Hardy-Weinberg equilibrium were examined for each population, at each locus, by calculating the Wright's fixation index $F_{\text {is }}$ as estimated by Weir \& Cockerham's (1984) $f$, using the same software. Departure from Hardy-Weinberg equilibrium was then tested using exact tests. Overall levels of genetic differentiation were analysed by calculating the estimator $\theta$ of Wright's $F_{\text {st }}$ statistic (Weir \& Cockerham 1984) for each locus, and the null hypothesis of identity of allelic distributions across populations was then tested using exact tests. Pairwise multilocus $\theta$ values were used to construct an UPGMA tree using Mega 2.1 software (Kumar et al. 2001); genetic distances were represented as a function $\theta /(1-\theta)$, following the recommendations of Rousset \& Raymond (1997). Isolation-by-distance and molecular variance between geographic groups 
( $F_{\mathrm{st}}$-based AMOVA) were also estimated following methods previously described for analysis of mtCOI haplotypes.

Biometry and demographic analyses. The internal disc diameter (IDD) represents the best descriptor of individual growth in this species (Guille 1964), and this measure was chosen to perform size-frequency histograms. IDD is defined as the distance between the distal extremities of a pair of radial shields and the middle of the line joining the base of the 2 pairs of diametrically opposed radial shields. IDD was measured under a binocular microscope with an eye micrometer at $12 \times$ magnification to the nearest $0.02 \mathrm{~mm}$. About 200 brittle stars from each of the 3 sites (Roscoff, Paluel and Wimereux) were measured every 2 mo (see exact sample sizes in the 'Results'). Individuals were grouped into $1 \mathrm{~mm}$ size classes for the analysis to maximize the number of size classes. The Normsep program of Tomlinson (1970) adapted by Glémarec \& Menesguen (1980) was used to identify modal components out of size-frequency histograms by fitting a set of normal rules to the observed distribution following the method of Bhattacharya (1967). Modal components were then assigned to cohorts from their subsequent positions in temporal samples and used to parameterise demographic functioning. Demographic results are detailed in Muths et al. (in press); only synthesized information helpful to understand the genetic pattern is presented.

\section{RESULTS}

\section{Existence of 2 geographical lineages inconsistent with known varieties}

\section{Mitochondrial COI sequences}

A NJ tree based on haplotypes of Ophiothrix fragilis is presented in Fig. 2. The topology of the tree indicates the occurrence of 2 highly divergent sets of mitochondrial sequences, the divergence of which was $18.6 \%$. In comparison, divergence between Ophiothrix sp. and Ophiocomina nigra (the outgroup) was $33.6 \%$. One set of sequences corresponded to the 6 individuals collected along the Mediterranean and Galician coasts (6 O.f. echinata individuals). The second set of sequences was quite homogeneous, with an average divergence of
$<1 \%$. Detailed topology of this clade regrouping all individuals from the 23 northern populations is presented in Fig. 2b. The topology of the tree shows a near-to-root clade that does not show any trace of 'old' divergence separating groups of haplotypes within this northern clade. All the varieties were grouped together with virtually no divergence among them. The AMOVA analyses performed on populations partitioned into varieties (Table 2) showed that classification by variety had no significant influence on the total mitochondrial variance $\left(\phi_{\mathrm{ct}}=0.000, \mathrm{p}=0.37\right)$.

\section{Allozymes}

A total of 7 polymorphic enzyme loci were screened over the whole set of populations. Allele frequencies are presented per locus and per population in Tables A1 \& A2 (Appendix 1, available at http://www.int-res.com/

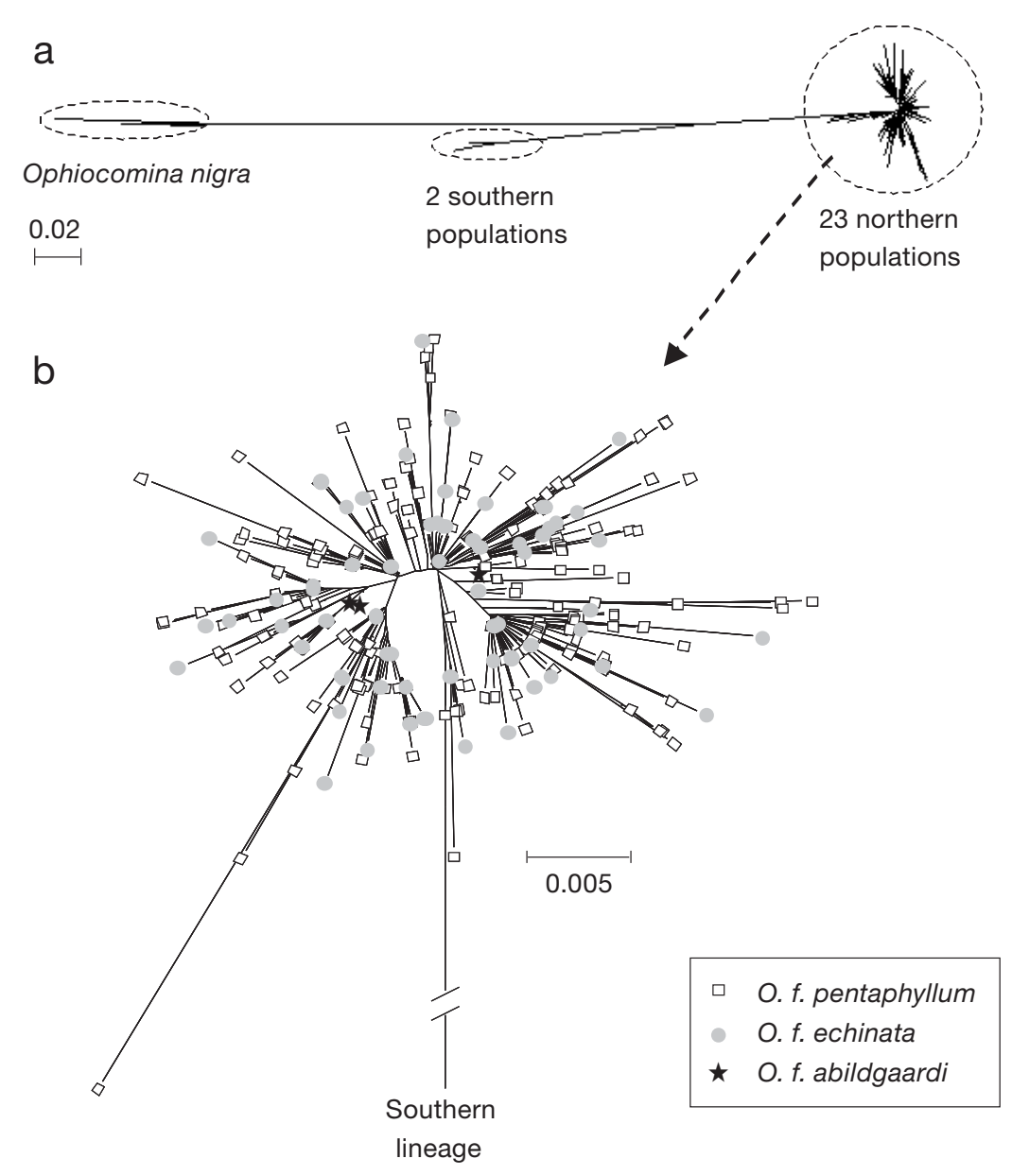

Fig. 2. Ophiothrix fragilis. (a) Neighbour-joining tree between mtCOI haplotypes of $O$. fragilis, using Ophiocomina nigra as an outgroup. (b) Cladegrouping haplotypes from the 23 northern populations (constituting a group with $<1 \%$ divergence). The tree is rooted with the second Ophiothrix lineage (i.e. Iberian specimens) 
Table 2. Ophiothrix fragilis. Hierarchical analyses of molecular variance (AMOVA) according to variety, geography, habitat, depth and recruitment events: pairwise genetic distances used were $\phi_{\mathrm{st}}$ for mtCOI and $\theta$ for allozymes

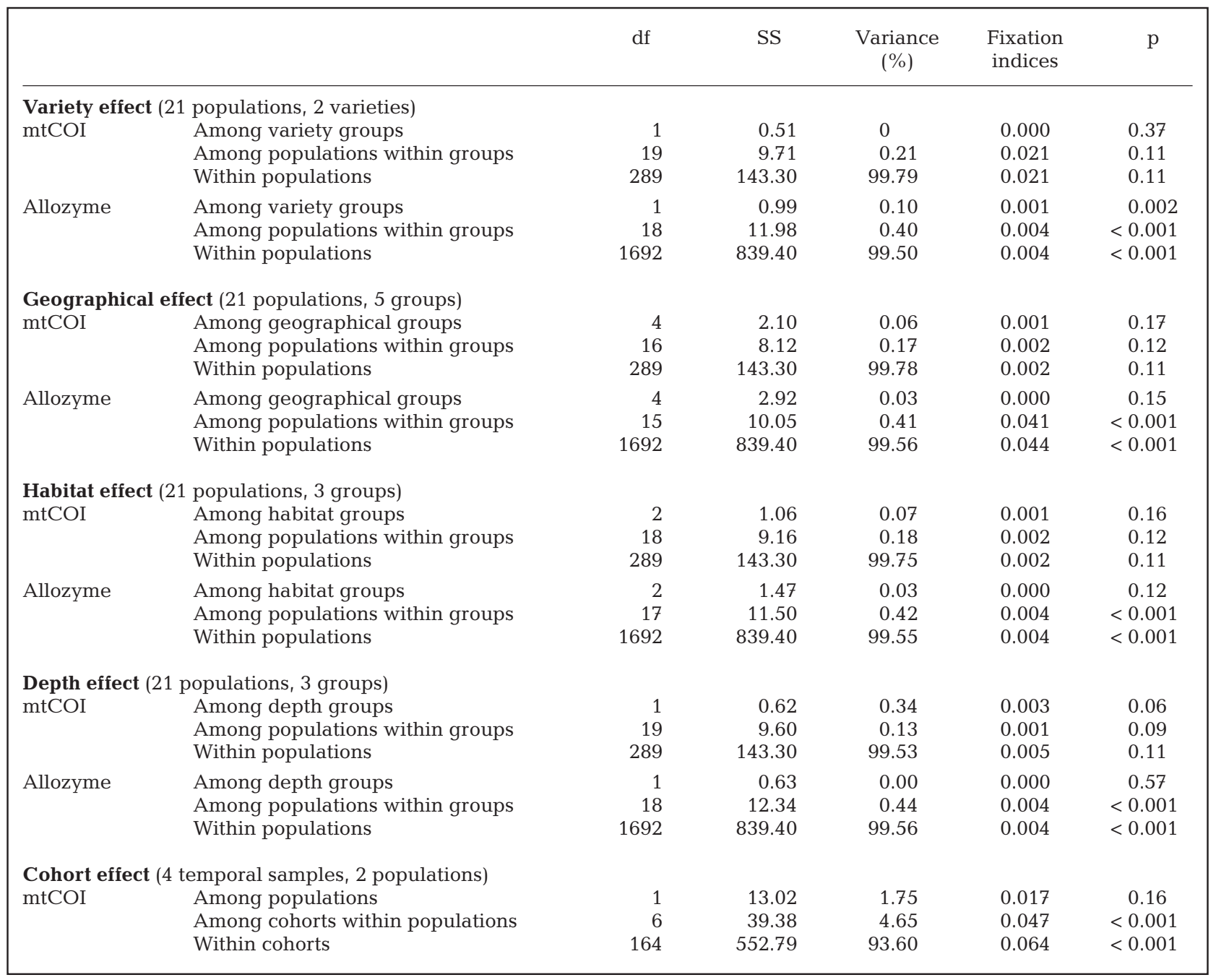

journals/suppl/b005p117_app.pdf) (Ophiothrix fragilis pentaphyllum and O. f. echinata, respectively). The canonical discriminant analysis (Fig. 3) indicated that, among explanatory variables, variety and depth were the only ones that remained significant after a forwardselection procedure (permutation test, $\mathrm{p}<0.05$ ). The 2 first factorial axes explained 18.57 and $13.58 \%$, respectively, of the $41.34 \%$ genetic variance extracted from populations (response variables). Classification by variety explained a substantial part of the total genetic variance in $O$. fragilis. The multiloci pairwise $\theta$ estimate between the 2 varieties was $0.023(\mathrm{p}<0.05)$; the monolocus $\theta$ estimates were all significant, with the highest value (0.122) for PK and the lowest value (0.005) for PGI. This genetic difference corresponded to a slight change in allele frequencies between varieties; O. f. pentaphyllum was characterized by a higher frequency of $P k 90$ $(f=0.260)$ and a lower frequency of $\operatorname{Mdh} 110(f=0.076)$ when compared to O. f. echinata $(f=0.096$ and $f=0.113$, for Pk90 and Mdh110, respectively). The MDH locus showed a similar, but less pronounced, trend. The AMOVA analyses performed on populations partitioned into varieties (Table 2 ) showed that a non-negligible part of the total allozyme variance was significantly associated with classification by variety $\left(\phi_{\mathrm{ct}}=0.001, \mathrm{p}=0.002\right)$. This reinforces previous observations made with the CDA analysis (Fig. 3), suggesting an association between some alleles and variety type that was not gleaned from the distribution of COI haplotypes. However, genetic variance could not be attributed to either of the environmental factors tested, i.e. depth or the nature of substratum (Table 2). Geographic proximity showed no significant influence, as most of the genetic variation was explained by intrapopulation heterogeneity $\left(\phi_{\mathrm{st}}=0.044\right.$, $\mathrm{p}<0.001$ ) and not by differentiation among geographic groups $\left(\phi_{\mathrm{ct}}=0.000, \mathrm{p}>0.05\right)$. 


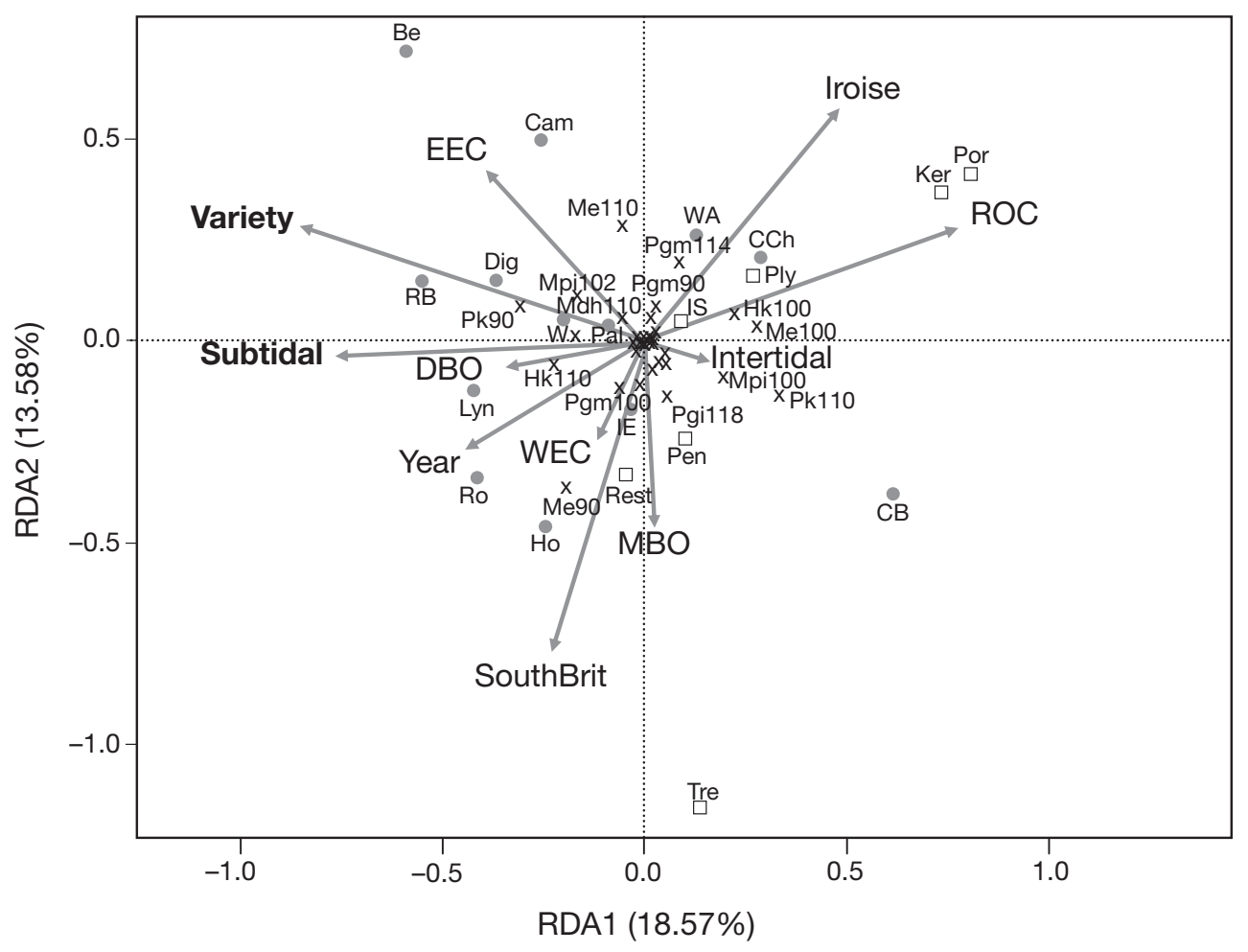

Fig. 3. Ophiothrix fragilis pentaphyllum, O. f. echinata. Canonical discriminant analysis, performed on allele frequencies and ecological descriptors of the northern populations of $O$. f. pentaphyllum and $O$. f. echinata. The percentages of variance explained by Axes 1 and 2 were 18.57 and $13.58 \%$, respectively. Explanatory variables are symbolized by vectors, with significant ones in bold, i.e. variety and subtidal. $\mathbf{x}$ : contributions of tested variables (i.e. genetic data); ๑: O.f. pentaphyllum; 口: O.f. echinata. Abbreviations, see Table 1

\section{Global genetic diversities within lineages}

The 2 most southern (Mediterranean Sea and Galician coast) and the 2 most northern (Norway and Sweden) populations of Ophiothrix fragilis were excluded from the following population genetics analyses due to the deep divergence and/or the small sample size.

\section{Mitochondrial COI sequences}

From the remaining dataset, 198 polymorphic sites were detected, corresponding to 289 distinct haplotypes. Of the polymorphic sites, $77.9 \%$ were parsimoniously informative and $22.1 \%$ were singletons. All populations showed a similarly high level of genetic diversity (Table 3). Mean haplotype diversity $\left(H_{\mathrm{d}}\right)$ and mean nucleotide diversity $(\pi)$ were of the same order of magnitude among populations, approximately 0.99 and 0.01 , respectively. The percentage of 'private' haplotypes was very high, with an average value of $67 \%$ that varied from 40 to $89 \%$ between samples and to a much lesser extent between geographic regions. Tajima's $D$ - and Fu's $F$-values were globally negative and significant $(D=-2.47, \mathrm{p}<0.001$ and $F=-4.80, \mathrm{p}<$ $0.02)$, indicating an excess of low-frequency variants that could be due either to a selective sweep or to population size expansion.
Table 3. Ophiothrix fragilis. Mitochondrial diversities for each population. $N_{\text {coi }}$ number of sequences; $h$ : number of haplotypes per population; $H_{\mathrm{d}}$ : haplotype diversity; $\pi$ : nucleotide diversity; private $(\%)$ : percentage of 'private' haplotypes

\begin{tabular}{|lccccc|}
\hline & $N_{\text {coi }}$ & $h$ & $H_{d}$ & $\pi$ & Private (\%) \\
\hline South Brittany & & & & & \\
$\quad$ Hoedig & 14 & 13 & 0.989 & 0.0135 & 0.62 \\
$\quad$ Houat & 14 & 14 & 1 & 0.0131 & 0.53 \\
$\quad$ Trevignon & 11 & 10 & 0.982 & 0.0113 & 0.64 \\
Iroise Sea & & & & & \\
$\quad$ Pentrez & 6 & 6 & 1 & 0.0086 & 0.50 \\
$\quad$ Cap de la Chevre & 12 & 11 & 0.985 & 0.0101 & 0.75 \\
Camaret & 15 & 12 & 0.978 & 0.0106 & 0.50 \\
$\quad$ Rade de Brest & 20 & 20 & 1 & 0.0107 & 0.65 \\
$\quad$ Ile Segal & 17 & 17 & 1 & 0.0122 & 0.76 \\
$\quad$ Portsall & 7 & 7 & 1 & 0.0079 & 0.71 \\
West English Channel & & & & & \\
$\quad$ Keremma & 10 & 10 & 1 & 0.0096 & 0.40 \\
$\quad$ Roscoff & 33 & 27 & 0.997 & 0.0126 & 0.78 \\
$\quad$ Restran & 13 & 12 & 0.987 & 0.0112 & 0.83 \\
$\quad$ Plymouth & 10 & 10 & 0.933 & 0.0113 & 0.75 \\
East English Channel & & & & & \\
$\quad$ Antifer & 9 & 9 & 1 & 0.0150 & 0.89 \\
$\quad$ Paluel & 21 & 21 & 1 & 0.0105 & 0.83 \\
$\quad$ Wimereux & 28 & 25 & 0.992 & 0.0105 & 0.67 \\
$\quad$ Belgium & 16 & 15 & 0.992 & 0.0097 & 0.62 \\
Irish Sea & & & & & \\
$\quad$ Cardigan Bay & 14 & 11 & 1 & 0.0111 & 0.71 \\
$\quad$ West Anglesey & 15 & 9 & 0.964 & 0.0114 & 0.71 \\
$\quad$ Lyna's Point & 16 & 15 & 0.992 & 0.0121 & 0.75 \\
Isle of Man East & 15 & 15 & 1 & 0.0113 & 0.67 \\
\hline & & & & & \\
\hline
\end{tabular}


Table 4. Ophiothrix fragilis pentaphyllum. Modal decomposition of populations summarizing the demographic dynamics of O.f. pentaphyllum at 3 localities in the English Channel. $\mathrm{n}$ : number of brittle stars measured; $x_{\mathrm{i}}$ : mean size of individuals in cohort $i$ (in $\mathrm{mm}$ ); \% $i$ (in grey): percentage of individuals in cohort $i$ compared to the whole sample at this date. Bold: cohorts that correspond to 'true' recruitment events

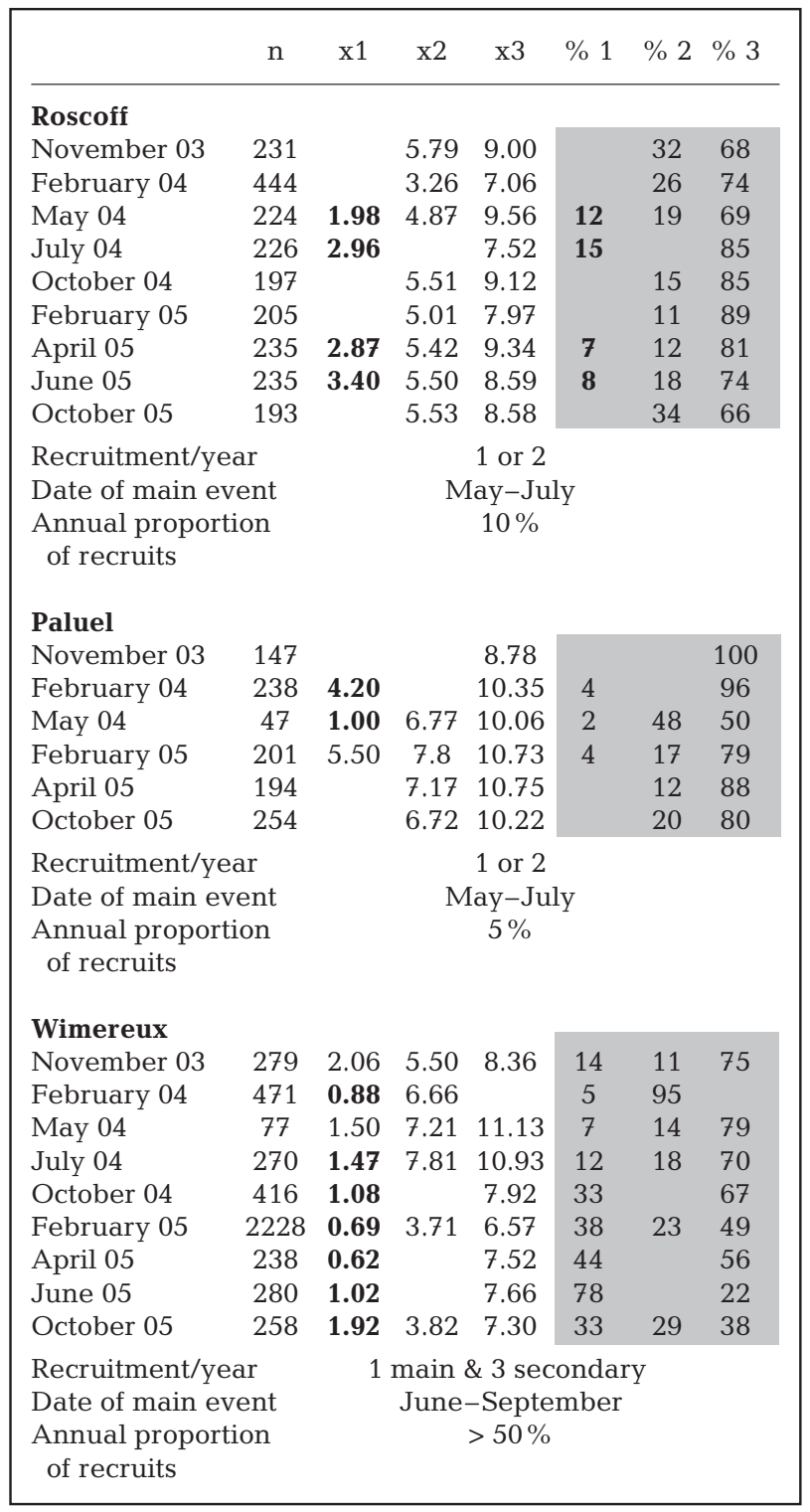

\section{Allozymes}

Together with allele frequencies, heterozygosities and $F_{\text {is, }}$ are presented in Tables A1 \& A2 (Ophiothrix fragilis pentaphyllum and O.f. echinata, respectively). The observed number of alleles was high and varied from 3 to 10 , with an average of $5.6( \pm 2.6)$ alleles. Allelic richness was similar among populations. Heterozygote deficiencies were highly significant in all populations, except in
Belgium and Camaret (Tables A1 \& A2). Values ranged from 0.015 for Belgium to 0.397 for Portsall. Significant heterozygote deficiencies were randomly distributed among loci, except for PK, for which a general trend of heterozygote excess was observed. Genotypic disequilibrium was not detected across loci over the whole dataset ( $p>0.05$ ), but genotypic disequilibrium was observed for some locus pairs within 9 O.f. pentaphyllum populations (Table A1). The involved loci were different from one population to another, but were more often found between PK and PGM or MPI loci. Linkage disequilibria did not always correspond to the loci involved in departures from Hardy-Weinberg equilibrium.

\section{Broad-scale patterns of geographic differentiation}

This part of the study was restricted to the dense subtidal populations of Ophiothrix fragilis pentaphyllum - the most abundant variety.

\section{Mitochondrial COI sequences}

The mitochondrial structure of Ophiothrix fragilis pentaphyllum was characterized by a high number of 'private' haplotypes and no clear geographic pattern. Pairwise $\phi_{\text {st }}$ estimates were on average very low (i.e. 0.01 ), with only $15 \%$ of the pairwise $\phi_{\text {st }}$ estimates being significant after a Bonferroni correction. All significant $\phi_{\text {st }}$ values were found with pairwise combinations that included samples from Camaret, Paluel, or Belgium, without any clear geographic signature. The less differentiated populations did not group with each other in the NJ tree of populations, and no isolation-by-distance relationship was detected in the dataset (Mantel test, $\mathrm{p}=0.22$ ).

\section{Allozymes}

Nearly all pairwise multilocus $\theta$ values between Ophiothrix fragilis pentaphyllum populations were significantly different $(0.007<\theta<0.166 ; 96 \%$ with $\mathrm{p}<$ $0.01)$. In the UPGMA tree representing pairwise $\theta$ estimates between populations (Fig. 4), neighbouring populations were often as genetically differentiated as distant populations, which explains the absence of any isolation-by-distance (Mantel test, $\mathrm{p}=0.78$ ). For example, individuals from Hoedig and Houat, only $15 \mathrm{~km}$ apart, and collected from the same depth and type of substratum, displayed greater levels of genetic differentiation than those collected from the Rade de Brest and the Isle of Man, separated by ca. $800 \mathrm{~km}$, and inhabiting different habitats and depths. 


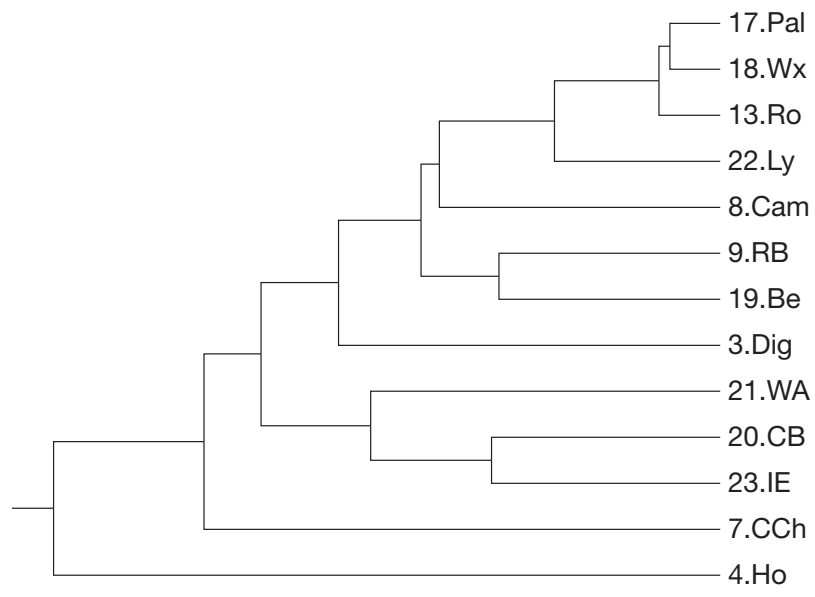

$\begin{array}{lllll}0.04 & 0.03 & 0.02 & 0.01 & 0.00\end{array}$

Fig. 4. Ophiothrix fragilis pentaphyllum. UPGMA tree showing the genetic relationship between populations using allozyme data (genetic distances were represented as a function $\theta /(1-\theta)$, following the recommendations of Rousset \& Raymond 1997). Abbreviations, see Table 1

Local-scale patterns of genetic differentiation: population demography and cohort differentiation

\section{Demographic analyses}

Modal decomposition of size-frequency histograms was carried out for the 3 well-surveyed localities in the English Channel (from west to east: Roscoff, Paluel and Wimereux). The evolution of modal components throughout the year revealed important differences in the demographic dynamics of the 3 populations. Temporal variation of mean length and cohort composition are summarized in Table 4. At Roscoff, samples were dominated by 2 types of individuals in both years: middle-sized individuals, with a modal length of ca. $5 \mathrm{~mm}$, and large-sized individuals, with a modal length of $9 \mathrm{~mm}$ corresponding to 1-yr-old adults and 2-yr-old (and older) adults, respectively (Davoult et al. 1990). Additional peaks were only observed between May and July, and represented sporadic arrivals of new recruits in the population (about $10 \%$ of the population). At Paluel, $>80 \%$ of the population was made of a unique group of adults (modal length of $10 \mathrm{~mm}$ ) from January to May. Recruitment events occurred several times a year in pulses of low numbers of settlers. In this case, recruits contributed to $<5 \%$ of the whole sample size. At Wimereux, recruitment events were massive and numerous ( 3 to 4 events $\mathrm{yr}^{-1}$ ), with large numbers of recruits throughout the year. Three recruitment events were observed in 2004, with a maximum in
September ( $40 \%$ of the population), and 4 recruitment events were observed in 2005, with a maximum in June ( $80 \%$ of the population). Because the adult mode was not always dominant, it seemed that the population turnover was more rapid at Wimereux than at Roscoff or Paluel.

\section{Mitochondrial COI sequences}

As several cohorts settled each year at Roscoff and Wimereux, genetic differentiation analysis was performed on samples from successive cohorts. An AMOVA analysis was therefore carried out to test whether the timing of settlement contributes to genetic differentiation within populations (Table 2). A nonnegligible part of the total mitochondrial variance was associated with cohorts, with fixation indices significantly differing from zero between cohorts of each population $\left(\phi_{\mathrm{sc}}=0.047, \mathrm{p}<0.001\right)$. Pairwise $\phi_{\mathrm{st}}$ estimates obtained between cohorts (i.e. larvae 2005, juvenile 2004 to 2006 and adult 2004) were generally significant (Table 5). At Roscoff, 1 significant $\phi_{\text {st }}$ value was found between larvae from 2005 and juveniles from 2004, whereas, at Wimereux, 4 out of $6 \phi_{\text {st }}$ values remained significant after Bonferroni correction. This strengthened our previous AMOVA results suggesting differences between cohorts. Haplotype NJ trees obtained from the Wimereux and Roscoff samples highlighted this finding and showed that samples from successive cohorts were more similar at Roscoff than at Wimereux (see Fig. 5). In this latter case, most juveniles from 2005 and 2006 were grouped into an independent cluster (upper part of Fig. 5) that excluded adults or juveniles from 2004.

Table 5. Ophiothrix fragilis pentaphyllum. Pairwise $\phi_{\text {st }}$ values from mtCOI sequences of O.f. pentaphyllum at Roscoff ( $\mathrm{n}=$ 105) and Wimereux $(n=66)$. Roscoff: adults 2004 (AR04), juveniles from May 2004 (JR04), June 2005 (JR05) and larvae from August 2005 (LR05); Wimereux: juveniles from October 2004 (JW04), 2005 (JW05) and 2006 (JW06) and adults 2004. ${ }^{*} \mathrm{p}<0.05 ;{ }^{* *} \mathrm{p}<0.01 ;{ }^{* * *} \mathrm{p}<0.001$

\begin{tabular}{|llll|}
\hline Roscoff & JR04 & LR05 & JR05 \\
\hline LR05 & $0.034^{*}$ & & \\
JR05 & 0.026 & 0.003 & \\
AR04 & 0.001 & 0.011 & -0.014 \\
\hline \hline Wimereux & JW04 & JW05 & JW06 \\
\hline JW05 & -0.010 & & \\
JW06 & $0.127^{*}$ & $0.077^{* * *}$ & \\
AW04 & $0.159^{* * *}$ & $0.103^{* * *}$ & 0.027 \\
\hline
\end{tabular}




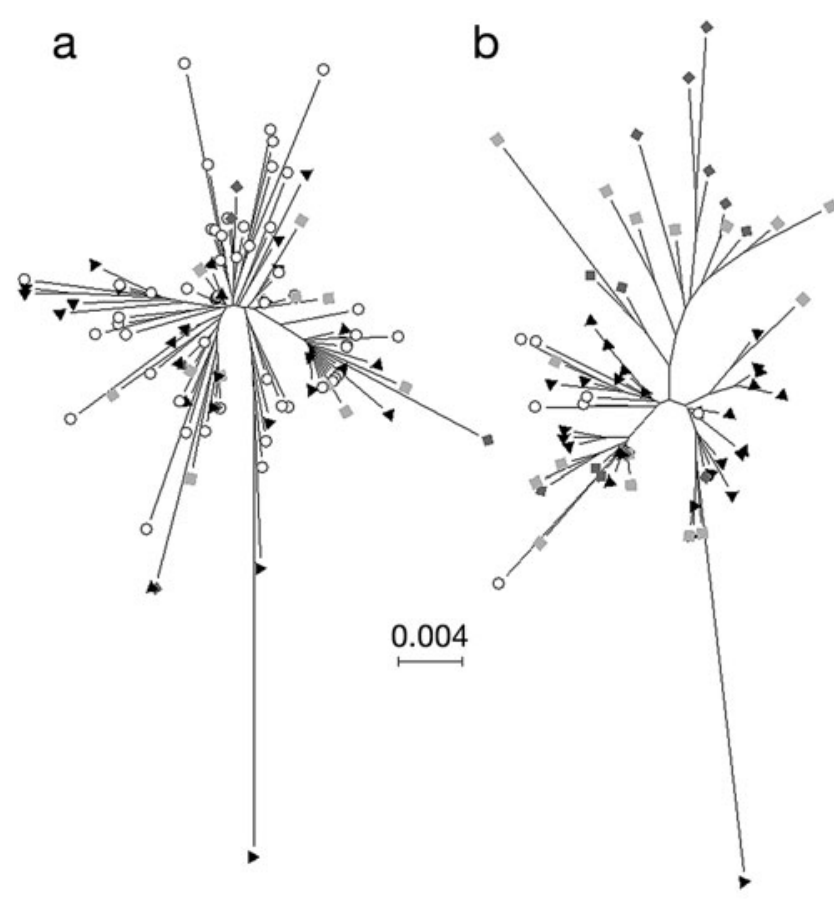

Fig. 5. Ophiothrix fragilis pentaphyllum. Unrooted neighbour-joining trees based on pairwise number of differences between haplotypes grouped according to their cohort of origin at (a) Roscoff and (b) Wimereux. $\mathbf{\Delta}$ : adults sampled in 2004 at both sites; O: larvae from August 2005 for Roscoff; and $\square$, juveniles from 2004 and 2005, respectively, for Roscoff; 口, $\square$ and O: juveniles from 2004, 2005 and 2006, respectively, for Wimereux

\section{DISCUSSION}

\section{Taxonomic status of varieties and geographic boundaries of sibling lineages}

Polymorphism and polychromatism have been observed in Ophiothrix fragilis at local scales (Koehler 1921, Allain 1974). Because of contrasting differences between individuals, the colour/shape polymorphism was used as the unique criterion defining 4 putative varieties typifying $O$. fragilis (Koehler 1921). Polymorphism may arise due to phenotypic plasticity in response to a heterogeneous environment (Baric \& Sturmbauer 1999, Pigliucci 2005). For example, considering arm length, autotomy is a typical self-defence mechanism for avoiding predation and thus may lead to plasticity in this particular character. Self-amputation may also function as a response to local environmental pressures, as it reduces individual volume in stressful conditions (Emson \& Wilkie 1980). The warm versus dark colour of individuals has also been reported to be greatly dependent on local conditions and associated with substratum and depth in particular (Allain 1974). One of the main objectives of the present study was to determine if varieties represent biological species (meaning genetically independent units) and thus whether $O$. fragilis sensu lato represents a species complex. If so, assortative mating would be expected and detected with our set of markers, as it has already been shown in polychromatic morphs within other marine invertebrates such as the colonial ascidian Pseudodistoma crucigaster (Tarjuelo et al. 2004) or the echinoderm Echinometra mathaei (Matsuoka \& Hatanaka 1991).

COI sequences revealed moderate to low genetic differences between 3 of the 4 morphological varieties described by Koehler (1921), namely Ophiothrix fragilis echinata, O. f. pentaphyllum and O. f. abildgaardi, but a very high level of genetic divergence between the southern (Iberian coast and Mediterranean sea) and northern (Irish Sea and English Channel) populations of the O. f. echinata variety. The level of mitochondrial divergence between these 2 allopatric lineages of $18.6 \%$ indicates the existence of cryptic species. The taxonomic status of the species $O$. fragilis has already been questioned by Baric \& Sturmbauer (1999) mainly in the Mediterranean Sea. By sequencing 9 individuals of $O$. fragilis both from the Adriatic and Irish Seas and 5 individuals of $O$. quinquemaculata from the Adriatic Sea only, they found 2 distinct, but cryptic, lineages within each of the 2 Ophiothrix species. According to these authors, the mitochondrial 16S divergence between Lineages I and II was sufficiently high (9 to $12 \%$ ) to represent biological species, within which the morphological species $O$. fragilis and O. quinquemaculata should be referred to as ecotypes. Since the Isle of Man sample we collected was taken just a few kilometres from the sampling by Baric \& Sturmbauer (1999), our northern Atlantic/Channel populations correspond to Lineage I (while nothing could be said regarding Lineage II). This cryptic divergence within species reinforces the vicariance hypothesis proposed by Jolly et al. (2006) for coastal species of the NE Atlantic. However, unlike the coastal polychaetes Pectinaria spp. and Owenia spp. (Jolly et al. 2006), the distributions of the cryptic lineages of $O$. fragilis do not seem to overlap at the entrance of the English Channel, rather they are separated along the coasts of Galicia, in a way similar to what was observed for the crab Carcinus maenas (Roman \& Palumbi 2004) and the mysid Mesopodopsis slabberi (Remerie et al. 2006).

The northern clade of Ophiothrix fragilis seems to represent a unique entity around the British Isles and up to Norway. Based on mitochondrial haplotypes, the varieties O. f. pentaphyllum, O. f. echinata and O. f. albigardii show high genetic homogeneity with intralineage distances $<1 \%$ and high levels of genetic diversity throughout all populations and all regions. 
The analysis of COI haplotypes indicated no divergent groups between the 3 varieties. Possible explanations for the absence of distinct haplotype groups in the $O$. fragilis complex are: (1) a selective sweep of an advantageous haplotype across variety boundaries, as shown in Drosophila spp. (Hilton et al. 1994) (but in that case we could assume to find a low haplotype diversity in all populations); (2) extreme asymmetric introgression of mitochondrial DNA among varieties, as previously reported to a lesser extent in Mytilus spp. by Rawson \& Hilbish (1998); or (3) the fact that varieties do not represent biological species. Given that allozyme frequencies were nearly identical between varieties, with the exception of 2 loci, for which a slight increase of the alleles Pk100 and Mdh110 in O. f. echinata populations was noted, the most parsimonious explanation is, however, to consider that $O$. fragilis represents a single, but plastic, species. The intervarietal distance using mtCOI was $<1 \%$, and the overall allozyme differentiation was very low (0.023), far less than differences previously observed between cryptic species of other echinoderms $-19.6 \%$ and $\theta=0.26$, respectively, within the Acrocnida brachiata species complex, (Muths et al. 2006), and $\theta=0.24$ within the Echinocardium cordatum species complex (Féral et al. 1995) and even less than differences encountered within a well-diagnosed species $(\theta=0.088$; Uthicke et al. 1998). Since neither genetic marker showed any diagnostic differences between varieties, varieties may crossbreed enough to prevent the formation of reproductively isolated demes. However, genomes remain porous even for long periods after speciation has been completed, allowing multiple opportunities for widespread introgression (Chan \& Levin 2005, Mallet 2005). Since diagnostic genes have not yet been detected, it is not possible to rule out the hypothesis of hybridizing taxa under the assumption that a complete mitochondrial introgression occurred from one lineage to another. Reproductive compatibility trials between varieties would also help to draw conclusions about the level of isolation between varieties and possible hybridization.

If the northern clade of Ophiothrix fragilis represents a single species, the slight but significant relationship between allele frequencies and varieties may indicate that diversifying selection is acting on at least 2 loci (i.e. PK and MDH). This could fit perfectly with the previous findings of Baric \& Sturmbauer (1999) suggesting that $O$. quinquemaculata and $O$. fragilis represent ecotypes (with differences within both lineages in the Mediterranean Sea explained by adaptation to various water depths). Diversifying selection may indeed be the direct consequence of the subtidal versus intertidal segregation of varieties (even if not total; Allain 1974). A great number of factors, including desiccation stress, temperature extremes, current strength, food composition and availability, competition among conspecifics and interspecific interactions may vary between habitats. These differing conditions influence the selective regime and thus may lead to the slight allele frequency differences observed between the 2 varieties $O . f$. echinata and O. f. pentaphyllum at the PK and MDH loci. Many additional studies focusing on this specific question are necessary to provide information on the status of varieties, the level of isolation between them and the role of environmental factors in their spatial segregation. Our results are first evidence for a genetic basis of the different varieties. Testing the sensitivity of each variety to environmental stress using ecophysiological experiments (as in Gardner \& Thompson 2001, Edmands \& Deimler 2004) could be one step towards determining whether varieties represent true ecotypes.

\section{Large-scale chaotic genetic patchiness: diversifying selection or isolation-by-time?}

Because of the low genetic differentiation between varieties, the spatial organisation of the genetic variance of Ophiothrix fragilis was only studied in the clearly identifiable variety $O$. f. pentaphyllum. The analysis of mitochondrial sequences revealed a very high level of haplotype diversity (nearly all individuals displayed distinct haplotypes), which can be attributed to a large effective population size that has not fluctuated very much over time (intricate network with several equally frequent haplotypes; data not shown). A large effective population size is congruent with the densities of up to 7500 ind. $\mathrm{m}^{-2}$ (Davoult \& Migné 2001) and fecundities of 190000 oocytes ovary ${ }^{-1}$ (Lefebvre 1999) recorded in this species. The lack of differentiation detected on a large spatial scale for the mtCOI gene is also in agreement with the assumption that large population sizes are not very sensitive to drift, which fits with our initial hypotheses on the considerable dispersal capabilities of $O$. fragilis larvae. The lack of nucleotide differentiation may also reflect the effect of high 'within-sample' diversity on 'betweensample' comparisons as noted by Charlesworth (1998) and Hedrick (1999), in comparison to the important and significant values of pairwise genetic differentiation found with allozymes.

The allozyme data, however, suggest that the distribution of Ophiothrix fragilis may not follow a $n$-islands model of populations at the scale studied, despite its relatively long-lived larval phase. This greatly contrasts with mtDNA data. The lack of genetic structure with mtDNA data could have several origins: (1) a high within-population structure, (2) a recent selective sweep 
(but in that case we could expect to find low haplotype diversity in all populations), or (3) a recent colonisation of the NE Atlantic. In contrast, allozyme differentiation could reflect: (1) geographic patterning, (2) diversifying selection in a heterogeneous environment, and/or (3) a patchwork of genetically differentiated populations (ongoing cryptic species) that does not crossbreed easily (due to some pre-zygotic barrier, e.g. a shift in spawning dates). Addison \& Hart (2004, 2005), for Strongylocentrotus droebachiensis, and Peijnenburg et al. (2006), for Sagitta setosa, also reported important disparities in gene diversities and genetic differentiation between mtDNA and microsatellites, and partly attributed their results to a cumulative signature of local processes of hybridization and the recent colonisation history of the area studied.

Despite high and significant values of fixation indices, either within or between populations, no geographic structure was identified either from allozymes (nearly all populations were differentiated) or from the haplotype distribution (nearly all populations were similar). In the former case, genetic differentiation appears to be chaotic, leading to important variations between localities without any spatial orientation. Indeed, most of the genetic variance is associated with the intrapopulation level. This genetic heterogeneity within populations can be due to a strong habitat effect (diversifying selection), the coexistence of genetically divergent groups (varieties) at a local scale or associated with the mixing of settlers from different geographic origins that would not be able to crossbreed (e.g. differing maturation periods due to a shift in recruitment), possibly leading to a Wahlund effect. A slight shift in the reproduction period of varieties, especially between the intertidal and subtidal zones, may be one explanation for heterozygote deficiencies if one considers that varieties are able to co-occur in both habitats but not to reproduce efficiently. A shift in spawning periods has already been described for other brittle stars living in both the subtidal and the intertidal (Bourgoin et al. 1991). Together with varietal selection, which would lead to a 'predictable' spatial structure, the main hypothesis, which can be invoked to explain chaotic genetic patchiness at such a scale, is the 'cohort effect' (Johnson \& Black 1984, David et al. 1997). In this case, the high level of genetic structure within populations may be explained by genetic differences between successive cohorts. In the present study, demographic surveys showed the occurrence of discrete recruitment events throughout a year, with a shift in these demographic events across the different localities in the Channel. This type of shift is congruent with the spatio-temporal variability in gonad growth reported by Lefebvre (1999), which suggests possible cohort admixture. A study of local hydrodynamics and larval dispersal of Ophiothrix fragilis in the English Channel (Lefebvre et al. 2003) showed that population replenishment could be mostly ensured by self-recruitment at some localities (e.g. Roscoff), but that currents also promote a large input of larvae of different origins (e.g. Wimereux). In the case of cohort admixture, 2 alternative hypotheses about settlers can be proposed: (1) brittle stars are not all mature at the same time and thus recruitment only reflects reproductive asynchrony, or (2) reproduction is highly synchronized locally, but highly dependent on the environment of populations, and thus the subsequent recruitments mostly reflect differences in the origin of the settlers (i.e. the case of allo-recruitment depending on the strength and direction of currents). The AMOVA analysis performed between 'cohorts' showed that recruitment heterogeneity accounts for a significant part of mitochondrial genetic variance within a population. These genetic differences between recruits appeared to be less pronounced at Roscoff than at Wimereux. This agrees with our population dynamics survey, which demonstrates great differences between the 2 localities, both in the number of recruitments per year and their intensity in respective populations. The rapid settler turnover at Wimereux is therefore more likely to generate an admixture of genetically differentiated cohorts. Because of important time lags between 2 successive recruitment events, mature adults originating from settlers from different origins may differ in their spawning periods over the year according to their settlement dates. This would prevent any further genetic re-homogenisation of the population through backcrosses in a way already proposed by Hendry \& Day (2005) and also shown for the European eel (Maes et al. 2006). In contrast, population turnover seems slower at Roscoff, and adults result from a single major recruitment event and are more likely to reproduce with each other during the following year. Spatial variation in population dynamics is therefore likely to affect the genetic signature of populations, either by attenuating or enhancing the 'cohort' effect locally. This has been invoked to explain chaotic genetic differentiation at a local spatial scale in the bivalve Spisula spp. (David et al. 1997), as well as patterns of temporal genetic heterogeneities for a variety of benthic marine invertebrates, first, on small spatial scales (Johnson \& Black 1982, Johnson \& Black 1984) and, later, on a larger geographical scale (Kordos \& Burton 1993, Moberg \& Burton 2000, Addison \& Hart 2004).

The present study highlights several non-exclusive hypotheses (diversifying selection on varieties, admixtures of cryptic possibly hybridizing species, or genetically different cohorts) to explain present-day patterns of differentiation in Ophiothrix fragilis along NE Atlantic coastlines. The co-occurrence of slightly dif- 
ferentiated ecotypic varieties or admixtures of temporally differentiated cohorts during the recruitment periods can be responsible for the lack of geographic structure and the observed heterozygote deficiencies. This could explain the apparent chaotic structure within $O$. fragilis populations. Our study provides additional information for better understanding how expected population homogenisation via long-distance larval dispersal may be masked by local processes influencing reproductive dynamics. The present study therefore reinforces previous hypotheses on the role played by recruitment heterogeneity in shaping the genetic signature of populations (David et al. 1997). More detailed studies on the genetic structure associated with size-stratified populations should be performed, in parallel to new approaches for identifying the origin of recruits (e.g. stable isotopes, as for fish species; Charles et al. 2004, Cook et al. 2007).

Acknowledgements. We are very grateful to everyone who helped us in collecting samples, in particular to the captains and crews of RVs 'Mysis' and 'Sepia II' for samples used in the demographic survey, J. Grall and C. Broudin for samples from Brittany, and C. Hubas for organising all the drives between Roscoff and Wimereux. Special thanks to Pierre Legendre, who helped us analyse the dataset, and to everyone who provided us with more 'exotic' samples: A. Carlier from the Mediterranean, J. Murillo Prez from Galicia, L. Dupont from Plymouth, R. Morgan from Belgium, S. Stöhr from Sweden and T. Brattegard from Norway. We also thank the 3 anonymous referees and T. Jolly, who helped us to greatly improve the manuscript. The English has been corrected by a professional scientific editor, Dr. Carolyn Engel (www.scitex.fr). This work was partly funded by the transversal actions (AT) of the national programme PNEC (coord. B. Planque and P. Lazure) and the GBIRM programme (coord. J.-P. Féral) of the European network MarBEF.

\section{LITERATURE CITED}

Addison JA, Hart MW (2004) Analysis of population genetic structure of the green sea urchin (Strongylocentrotus droebachiensis) using microsatellites. Mar Biol 144: 243-251

Addison JA, Hart MW (2005) Colonization, dispersal, and hybridization influence phylogeography of North Atlantic sea urchins (Strongylocentrotus droebachiensis). Evolution 59:532-543

Allain JY (1974) Ecologie des bancs d'Ophiothrix fragilis (Abildgaard) (Echinodermata, Ophiuroidea) dans le golfe normano-breton. Cah Biol Mar 15:255-273

> Arndt A, Smith MJ (1998) Genetic diversity and population structure in two species of sea cucumber: differing patterns according to mode of development. Mol Ecol 7: 1053-1064

Baric S, Sturmbauer C (1999) Ecological parallelism and cryptic species in the genus Ophiothrix derived from mitochondrial DNA sequences. Mol Phylogen Evol 11:157-162

Benjamini Y, Hochberg Y (1995) Controlling the false discovery rate: a practical and powerful approach to multiple testing. J R Stat Soc Ser B 57:289-300

Bhattacharya CG (1967) A simple method of resolution of a distribution into Gaussian components. Biometrics 23:115-135
Bourgoin A, Guillou M, Glémarec M (1991) Environmental instability and demographic variability in Acrocnida brachiata (Echinoderma: Ophuiroidea) in Douarnenez Bay (Britanny: France). PSZN I: Mar Ecol 12:89-104

Bowen B, Bass A, Muss A, Carlin J, Robertson D (2006) Phylogeography of two Atlantic squirrelfishes (Family Holocentridae): exploring links between pelagic larval duration and population connectivity. Mar Biol 149:899-913

Briggs J (1995) Global biogeography. In: Develoments in paleontology and stratigraphy. Elsevier, Amsterdam, p 452

Broom DM (1975) Aggregation behaviour of the brittle star Ophiothrix fragilis. J Mar Biol Assoc UK 55:191-197

Brun E (1969) Aggregation of Ophiothrix fragilis (Abildgaard) (Echinodermata: Ophiuroidea). Norw J Zool 17:153-160

Cabioch L (1968) Contribution à la connaissance des peuplements benthiques de la Manche Occidentale. Cah Biol Mar 9:493-720

Chan KM, Levin SA (2005) Leaky prezygotic isolation and porous genomes: rapid introgression of maternally inherited DNA. Evolution 59:720-729

Charles K, Roussel JM, Cunjak RA (2004) Estimating the contribution of sympatric anadromous and freshwater resident brown trout to juvenile production. Mar Freshw Res 55:185-191

Charlesworth B (1998) Measures of divergence between populations and the effect of forces that reduce variability. Mol Biol Evol 15:538-543

Chevillon C, Rivet Y, Raymond M, Rousset F, Smouse PE, Pasteur N (1998) Migration/selection balance and ecotypic differentiation in the mosquito Culex pipiens. Mol Ecol 7:197-208

Cook B, Bunn S, Hughes J (2007) Molecular genetic and stable isotope signatures reveal complementary patterns of population connectivity in the regionally vulnerable southern pygmy perch (Nannoperca australis). Biol Conserv 138:60-72

Cowen RK, Lwiza KM, Sponaugle S, Paris CB, Olson DB (2000) Connectivity of marine populations: open or closed? Science 287:857-859

> David P, Perdieu M, Pernot A, Jarne P (1997) Fine-grained spatial and temporal population genetic structure in the marine bivalve Spisula ovalis. Evolution 51:1318-1322

> Davoult D, Gounin F (1995) Suspension-feeding activity of a dense Ophiothrix fragilis (Abildgaard) population at the water-sediment interface: time coupling of food availability and feeding behaviour of the species. Estuar Coast Shelf Sci 41:567-577

Davoult D, Migné A (2001) Respiration and excretion of a dense Ophiothrix fragilis population in the Bay of Seine (English Channel, France). In: Barker (ed) Echinoderms 2000. Swets \& Zeitlinger, Lisse, p 243-248

$>$ Davoult D, Gounin F, Richard A (1990) Population dynamics and reproduction of Ophiothrix fragilis (Abildgaard) in the Strait of Dover (English Channel). J Exp Mar Biol Ecol 138: 201-216

Dray S (2004) Packfor. R package, Version 0.0-6. Available at: http://biomserv.univ-lyon1.fr/dray/Software.html\#packfor

Eckert GL (2007) Spatial patchiness in the sea cucumber Pachythyone rubra in the California Channel Islands. J Exp Mar Biol Ecol 348:121-132

> Edmands S, Deimler JK (2004) Local adaptation, intrinsic coadaptation and the effects of environmental stress on interpopulation hybrids in the copepod Tigriopus californicus. J Exp Mar Biol Ecol 303:183-196

Ellien C, Thiébaut E, Barnay AS, Dauvin JC, Gentil F, Salomon JC (2000) The influence of variability in larval dispersal on the dynamics of a marine metapopulation in the 
eastern Channel. Oceanol Acta 23:423-442

Ellis JR, Rogers SI (2000) The distribution, relative abundance and diversity of echinoderms in the eastern English Channel, Bristol Channel and Irish Sea. J Mar Biol Assoc UK 80: 127-138

Emson RH, Wilkie IC (1980) Fission and autotomy in echinoderms. Oceanogr Mar Biol Annu Rev 18:155-250

Excoffier L, Smouse P, Quattro J (1992) Analysis of molecular variance inferred from metric distances among DNA haplotypes: application to human mitochondrial DNA restriction data. Genetics 131:479-491

Féral JP, Poulin E, Derelle E, Gallardo S, Chambon C (1995) Genetic differentiation of Echinocardium cordatum as revealed by allozymes and RNA sequencing. In: Emson SC (ed) Echinoderm research 1995. Balkema, Rotterdam, p 41-42

Fu Y (1997) Statistical tests of neutrality of mutations against population growth, hitchhiking and background selection. Genetics 147:915-925

Gaines SD, Bertness MD (1992) Dispersal of juveniles and variable recruitment in sessile marine species. Nature 360: 579-580

- Gardner JPA, Thompson RJ (2001) The effects of coastal and estuarine conditions on the physiology and survivorship of the mussels Mytilus edulis, $M$. trossulus and their hybrids. J Exp Mar Biol Ecol 265:119-140

Glémarec M, Menesguen A (1980) Functioning of a muddy sand ecosystem: seasonal fluctuations of different trophic levels and difficulties in estimating production of the dominant macrofauna species. In: Tenore KR, Coull BC (eds) Marine benthic dynamics. University of South Carolina Press, Columbia, SC, p 49-68

Goudet J (1995) FSTAT (Vers. 1.2): a computer program to calculate F-statistics. J Hered 86:485-486

Guille A (1964) Contribution à l'étude de la systématique et de l'écologie d'Ophiothrix quinquemaculata. Vie Milieu 15:243-309

Hall TA (1999) BioEdit: a user-friendly biological sequence alignment editor and analysis program for Windows 95/ 98/NT. Nucleic Acids Symp Ser 41:95-98

Hedgecock D (1994) Temporal and spatial genetic structure of marine animal populations in the California current. Calif Coop Fish Investig Rep 35:73-81

Hedrick PW (1999) Perspective: highly variable loci and their interpretation in evolution and conservation. Evolution 53: 313-318

Hellberg ME, Burton RS, Neigel JE, Palumbi SR (2002) Genetic assessment of connectivity among marine populations. Bull Mar Sci 70:273-290

Hendry AP, Day T (2005) Population structure attributable to reproductive time: isolation by time and adaptation by time. Mol Ecol 14:901-916

Hilton H, Kliman RM, Hey J (1994) Using hitchhiking genes to study adaptation and divergence during speciation within the Drosophila melanogaster species complex. Evolution 48:1900-1913

> Johnson MS, Black R (1982) Chaotic genetic patchiness in an intertidal limpet, Siphonaria sp. Mar Biol 70:157-164

Johnson MS, Black KD (1984) Pattern beneath chaos: the effect of recruitment on genetic patchiness in an intertidal limpet. Evolution 38:1371-1383

Jolly MT, Viard F, Weinmayr G, Gentil F, Thiebaut E, Jollivet D (2003) Does the genetic structure of Pectinaria koreni (Polychaeta: Pectinariidae) conform to a source-sink metapopulation model at the scale of the Baie de Seine? Helgol Mar Res 56:238-246

Jolly MT, Viard F, Gentil F, Thiebaut E, Jollivet D (2006) Com- parative phylogeography of two coastal polychaete tubeworms in the North East Atlantic supports shared history and vicariant events. Mol Ecol 15:1841-1855

> Kimura M (1980) A simple method for estimating evolutionary rates of base substitutions through comparative studies of nucleotide sequences. J Mol Evol 16:111-120

Kinlan BP, Gaines SD, Lester SE (2005) Propagule dispersal and the scales of marine community processes. Divers Distrib 11:139-148

Knowlton N (1993) Sibling species in the sea. Annu Rev Ecol Syst 24:189-216

Koehler R (1921) Faune de France-echinodermes, Vol 1. Lechevalier, Paris

> Kordos L, Burton R (1993) Genetic differentiation of Texas Gulf coast populations of the blue crab Callinectes sapidus. Mar Biol 117:227-233

Kumar S, Tamura K, Jakobsen I, Nei M (2001) MEGA2: molecular evolutionary genetics analysis software. Bioinformatics 17:1244-1245

Kyle C, Boulding E (2000) Comparative population genetic structure of marine gastropods (Littorina spp.) with and without pelagic larval dispersal. Mar Biol 137:835-845

Lefebvre A (1999) Reproduction d'une espèce benthique à phase larvaire planctonique, l'ophiure Ophiothrix fragilis (echinoderme), dans un système côtier à fort hydrodynamisme (détroit du Pas-de-Calais): interactions physique-biologie et implications dans le fonctionnement global de l'écosystème. PhD dissertation, University of Lille 1, Lille

Lefebvre A, Davoult D (2000) Larval distribution of Ophiothrix fragilis (Echinodermata: Ophiuroidea) in a macrotidal area, the Dover Strait (eastern English Channel, France). J Mar Biol Assoc UK 80:567-568

Lefebvre A, Ellien C, Davoult D, Thiébaut E, Salomon JC (2003) Pelagic dispersal of the brittle star Ophiothrix fragilis larvae in a megatidal area (English Channel, France) using an advection/diffusion model. Estuar Coast Shelf Sci 57:421-433

> Maes GE, Pujolar JM, Hellemans B, Volckaert FA (2006) Evidence for isolation by time in the European eel (Anguilla anguilla L.). Mol Ecol 15:2095-2107

Mallet J (2005) Hybridization as an invasion of the genome. Trends Ecol Evol 20:231-237

Marko PB (2004) What's larvae got to do with it? Disparate patterns of post-glacial population structure in two benthic marine gastropods with identical dispersal potential. Mol Ecol 13:597-611

Matsuoka N, Hatanaka T (1991) Molecular evidence for the existence of four sibling species within the sea-urchin, Echinometra mathaei in Japanese waters and their evolutionary relationships. Zool Sci 8:121-133

McBride CW (1907) The development of Ophiothrix fragilis. Q J Microsc Sci 51:557-606

McCarthy C (1997) Chromas, Ver 1.41. Griffith University, Brisbane

> McMillan WO, Raff RA, Palumbi SR (1992) Population genetic consequences of developmental evolution in sea urchins (genus Heliocidaris). Evolution 46:1299-1312

McMullin E, Hourdez S, Schaeffer S, Fisher C (2003) Phylogenetics and biogeography of deep-sea vestimentiferan tubeworms and their bacterial symbionts. Symbiosis 34: $1-41$

Moberg PE, Burton RS (2000) Genetic heterogeneity among adult and recruit red sea urchins, Strongylocentrotus franciscanus. Mar Biol 136:773-784

Morgan R, Jangoux M (2002) Reproductive cycle and spawning induction in the gregarious brittle star Ophiothrix 
fragilis (Echinodermata) in the Oosterschelde (Netherlands). Invertebr Reprod Dev 42:145-155

Morgan R, Jangoux M (2005) Larval morphometrics and influence of adults on settlement in the gregarious ophiuroid Ophiothrix fragilis (Echinodermata). Biol Bull 208:92-99

Muths D, Davoult D, Gentil F, Jollivet D (2006) Incomplete cryptic speciation between intertidal and subtidal morphs of Acrocnida brachiata (Echinoderm: Ophiuroidea) in the North East Atlantic. Mol Ecol 15:3303-3318

Muths D, Jollivet D, Davoult D (in press) Population dynamics disparities of the common brittle star Ophiothrix fragilis between three localities of the English Channel. In: Harris LG (ed) Proc 12th Int Echinoderm Conf, Durham, NH, 7-11 August 2006

Nataf G (1954) Les Ophiothrix fragilis (Echinodermes) de Roscoff. Bull Mus Natl Hist Nat 2 26:632-637

Nei M (1987) Molecular evolutionary genetics. Columbia University Press, New York

Oksanen J, Kindt R, Legendre P, O'Hara B, Simpson GL, Stevens MHH (2008) Vegan: community ecology package. R Foundation for Statistical Computing, Vienna. http://www.Rproject.org

Pasteur N, Pasteur G, Bonhomme F, Catalan J, BrittonDavidan J (1987) Manuel technique de génétique par électrophorèse des protéines. Lavoisier, Paris

Peijnenburg K, Fauvelot C, Breeuwer J, Menken B (2006) Spatial and temporal genetic structure of the planktonic Sagitta setosa (Chaetognatha) in European seas as revealed by mitochondrial and nuclear DNA markers. Mol Ecol 15:3319-3338

Pigliucci M (2005) Evolution of phenotypic plasticity: where are we going now? Trends Ecol Evol 20:481-486

Rawson PD, Hilbish TJ (1998) Asymmetric introgression of female and male lineage mitochondrial DNA(mtDNA) haplotypes within the European hybrid zone between Mytilus edulis and M. galloprovincialis. Evolution 52: 100-108

Raymond M, Rousset F (1999) GENEPOP (Ver 1.2): population genetics software for exact tests and ecumenicism. J Hered 86:248-249

Remerie T, Bourgois T, Peelaers D, Vierstraete A, Vanfleteren J, Vanreusel A (2006) Phylogeographic patterns of the mysid Mesodopsis slabberi (Crustacea, Mysida) in Western Europe: evidence for high molecular diversity and cryptic speciation. Mar Biol 149:465-481 doi:10.1007/ S00227-005-0235-7

Roman J, Palumbi SR (2004) A global invader at home: population structure of the green crab, Carcinus maenas, in

Editorial responsibility: Matthias Seaman, Oldendorf/Luhe, Germany
Europe. Mol Ecol 13:2891-2898

Rousset F, Raymond M (1997) Statistical analyses of population genetic data: new tools, old concepts. Trends Ecol Evol 12:313-317

Rozas J, Sanchez-DelBarrio JC, Messeguer X, Rozas R (2003) DnaSP, DNA polymorphism analyses by the coalescent and other methods. Bioinformatics 19:2496-2497

Rumrill SS (1990) Natural mortality of marine invertebrate larvae. Ophelia 32:163-198

Salomon JC (1990) Role of instantaneous and long-term water movements on the recruitment and life of benthic fauna in the English Channel. Mer (Paris) 28:211-217

Schneider S, Roessli D, Excoffier L (2001) Arlequin (V 2.0): software for population genetics data analysis. Genetics and Biometry Laboratory, Department of Anthropology, University of Geneva, Geneva

Sponaugle S, Cowen RK, Shanks A, Morgan SG and others (2002) Predicting self-recruitment in marine populations: biophysical correlates and mechanisms. Bull Mar Sci 70: 341-375

Tajima F (1989) Statistical method for testing the neutral mutation hypothesis by DNA polymorphism. Genetics 123:585-595

Tarjuelo I, Posada D, Crandall KA, Pascual M, Turon X (2004) Phylogeography and speciation of colour morphs in the colonial ascidian Pseudodistoma crucigaster. Mol Ecol 13: 3125-3136

Ter Braak CJF, Smilauer P (2002) CANOCO reference manual and CanoDraw for Windows user's guide: software for canonical community ordination (Ver 4.5). Ithaca, NY

Thompson JD, Higgins DG, Gibson TJ (1994) CLUSTAL W: improving the sensitivity of progressive multiple sequence alignment through sequence weighting, positions-specific gap penalties and weight matrix choice. Nucleic Acids Res 22:4673-4680

> Todd CT, Lambert WJ, Thorpe JP (1998) The genetic structure of intertidal populations of two species of nudibranch molluscs with planktotrophic and pelagic lecithotrophic larval stages: are pelagic larvae 'for' dispersal? J Exp Mar Biol Ecol 228:1-28

Tomlinson PK (1970) Program Normsep (Fortran IV). Dept Fish and Game, The resources agency of California, Sacramento, CA

Uthicke S, Benzie JAH, Ballment E (1998) Genetic structure of fissiparous populations of Holothuria (Halodeima) atra on the Great Barrier Reef. Mar Biol 132:141-151

Weir BS, Cockerham CC (1984) Estimating F-statistics for the analysis of population structure. Evolution 38:1358-1370

Submitted: November 23, 2007; Accepted: January 7, 2009

Proofs received from author(s): March 3, 2009 